\title{
Anatomia dos órgãos vegetativos como subsídios à taxonomia de Geissospermum (Apocynaceae - Rauvolfioideae)
}

\author{
Anatomy of the vegetative organs as subsidy to the taxonomy \\ of Geissospermum (Apocynaceae - Rauvolfioideae)
}

\author{
Breno Ricardo Serrão da Silva ${ }^{1,4}$, André dos Santos Bragança Gil ${ }^{2}$ \& André Olmos Simões ${ }^{3}$
}

\begin{abstract}
Resumo
Considerando as semelhanças morfológicas interespecíficas em Geissospermum e a dificuldade de coletar e consultar espécimes férteis, este trabalho visa detectar potenciais caracteres diagnósticos para o grupo através da análise de órgãos vegetativos. Para tal, amostras caulinares e foliares de G. argenteum, G. laeve, G. reticulatum, G. sericeum, e G. urceolatum foram coletadas de exsicatas incorporadas nos herbários HAMAB, INPA e MG e processadas segundo técnicas usuais de anatomia vegetal. As espécies foram comparadas mediante uma matriz binária de caracteres e submetidas a métodos de agrupamento (UPGMA) para obtenção de fenograma e, posteriormente, confeccionada uma chave de identificação dicotômica para as espécies estudadas. A análise fenética mostrou que as espécies mais semelhantes anatomicamente são G. argentem e G. sericeum, G. laeve e G. reticulatum, sendo G. urceolatum a mais distinta entre elas. Nossos resultados demonstram que a anatomia dos órgãos vegetativos contribuiu na identificação das espécies de Geissospermum, mesmo na ausência de órgãos reprodutivos. O formato das células epidérmicas, persistência dos tricomas, disposição dos braquiesclereídeos, contorno e vascularização do pecíolo foram as características mais importantes no reconhecimento dos taxa.

Palavras-chave: Amazônia, Aspidospermeae, Gentianales, Mata Atlântica.
\end{abstract}

\begin{abstract}
Considering the interspecific morphological similarities in Geissospermum and the difficulty of collecting fertile specimens of the genus, this work aimed to provide potential diagnostic anatomical characters for the group based on the analysis of vegetative organs. For this, stem and leaf samples of G. argenteum Woodson, G. laeve (Vell.) Miers, G. reticulatum A.H. Gentry, G. sericeum Miers, and G. urceolatum A.H. Gentry were collected from exsicates deposited at the herbaria HAMAB, INPA and MG and processed according to standard plant anatomy techniques. The studied species were then compared on a binary matrix of characters submitted to methods of grouping (UPGMA) to obtain a phenogram and, posteriorly, a dichotomous identification key. Our phenotype analysis showed that the most similar anatomically species are G. argenteum with $G$. sericeum, G. laeve with G. reticulatum, and G. urceolatum being the most distinct species in the genus. Our results show that the anatomy contributed to the identification of Geissospermum, even in the absence of reproductive organs. The epidermal cell shape, persistence of trichomes, brachycleral arrangement, contour and vascularization of the petiole were the most important features to the recognition of taxa within the taxa.
\end{abstract}

Key words: Amazonia, Aspidospermeae, Gentianales, Atlantic forest.

\footnotetext{
${ }^{1}$ Universidade Federal Rural da Amazônia, Prog. Pós-graduação em Ciências Biológicas, Área de concentração: Botânica Tropical, Av. Perimetral 2501, Terra Firme, 66077-830, Belém, PA, Brasil.

${ }^{2}$ Museu Paraense Emílio Goeldi, Coord. Botânica, Av. Perimetral 1901, Terra Firme, 66077-830, Belém, PA, Brasil.

${ }^{3}$ Universidade Estadual de Campinas, Inst. Biologia, R. Monteiro Lobato 255, Cidade Universitária, 13083-862, Campinas, SP, Brasil.

${ }^{4}$ Autor para correspondência: brenorss@hotmail.com
} 


\section{Introdução}

Geissospermum Allemão, pertencente à família Apocynaceae, compreende sete espécies: $G$. argenteum Woodson, G. fuscum Markgr. G. laeve (Vell.) Miers, G. reticulatum A.H., G. sericeum Miers, G. urceolatum A.H. Gentry e G. vellosii Allemão. Todas essas espécies são encontradas em floresta de terra firme no domínio fitogeográfico da Amazônia, sendo que apenas $G$. laeve também ocorre em Mata Atlântica (BFG 2015).

O gênero está inserido na tribo Aspidospermeae Miers, reconhecida como a primeira em ordem de divergência na subfamília Rauvolfioideae, junto com Aspidosperma Mart. \& Zucc, Haplophyton A. DC., Microplumeria Baill., Strempeliopsis Benth. e Vallesia Ruiz \& Pav. (Endress et al. 2014). Ainda nessa classificação, Geissospermum e Aspidosperma são considerados como prováveis gêneros afins pelo hábito arbóreo e folhas com filotaxia alterna, sendo diferenciados pelos frutos carnosos e bacoides em Geissospermum e folículos secos em Aspidosperma.

Apesar do conhecimento taxonômico sobre Geissospermum (Woodson 1939; Gentry 1984; Barbosa 2016), a distinção entre suas espécies ainda é confusa. Na maioria dos casos, são necessárias amostras contendo órgãos reprodutivos para sua diferenciação (Woodson 1939; Gentry 1984), o que nem sempre ocorre nas coletas em campo e nas coleções de herbário, já que as espécies do gênero não costumam florescer todos os anos (Barbosa 2016). Por vezes, a identificação em nível de espécie é imprecisa, principalmente, quando há órgãos reprodutivos de apenas um tipo (ou flores, ou frutos) (Woodson 1939; Barbosa 2016). Desta forma, estudos anatômicos dos órgãos vegetativos podem prover caracteres diagnósticos para as espécies de Geissospermum, complementares aos caracteres morfológicos tradicionalmente usados, facilitando o reconhecimento e identificação dos taxa.

Alguns trabalhos na família utilizam os caracteres anatômicos vegetativos com êxito na taxonomia. Entre eles, podemos citar os estudos anatômicos das folhas de Aspidosperma (Reis et al. 2013) e Forsteronia G. Mey (Rio et al. 2005), a arquitetura foliar de 29 espécies pertencentes a 19 gêneros da família (Mohan \& Inamdar 1982), além das obras tradicionais de Solereder (1908) e Metcalfe \& Chalk (1979), que reúnem os caracteres anatômicos das principais famílias de angiospermas.
Diante disso, este trabalho tem por objetivo caracterizar anatomicamente os órgãos vegetativos de cinco espécies de Geissospermum e detectar potenciais caracteres diagnósticos para auxiliar a identificação das espécies.

\section{Material e Métodos}

Amostras de caules e folhas completamente expandidas de Geissospermum foram coletadas de exsicatas proveniente dos herbários HAMAB, INPA e MG (Tab. 1), com a devida autorização dos curadores. As siglas dos herbários estão abreviadas segundo Index Herbariorum (Thiers, continuamente atualizado). Todos os espécimes tiveram sua identificação confirmada por especialista da família.

O material coletado foi processado por técnicas usuais de reversão de herborização (Smith \& Smith 1942) e destinado aos procedimentos anatômicos. Para cada característica analisada, foram utilizados três ou mais indivíduos por espécie, com exceção de G. reticulatum, para a qual foram analisados dois indivíduos.

Fragmentos da região mediana do limbo foliar, pecíolo e caule seguiram desidratação etílica para inclusão em hidroxietil-metacrilato (Historesin, Leica, Heidelberg, Germany), de acordo com o manual do fabricante. Seções transversais e longitudinais de $5 \mu \mathrm{m}$ foram obtidas com auxílio de micrótomo rotativo (RM 2245, Leica, Nussloch, Germany) e corados com azul de toluidina com tampão acetato de sódio $0,1 \mathrm{M} \mathrm{pH}$ 4,8 (O’Brien et al. 1965).

Para o estudo epidérmico, amostras do terço médio dos limbos foliares foram submetidas à solução de Franklin (Franklin 1945) durante 24h, coradas com Azul de Astra e montadas em glicerina aquosa (1:1) (Johansen 1940). Para o estudo de material macerado, fragmentos de caule foram submetidos à solução de Franklin (Franklin 1945) durante $24 \mathrm{~h}$, macerados, corados com Safranina alcóolica $1 \%$ e montadas em glicerina aquosa (1:1) (Johansen 1940).

Folhas inteiras e fragmentos da região apical, mediana e basal das espécies estudadas foram destinadas para os estudos de venação seguindo as recomendações de Fuchs (1963). Para as descrições dos padrões de venação seguiu-se a circunscrição de Hickey (1973).

As fotomicrografias foram obtidas através de câmera digital (Power Shot A640, Canon, Shanghai, China) acoplada a microscópio óptico (Axiolab, Zeiss, Jena, Germany). Alguns cortes 
Tabela 1 - Dados sobre os espécimes estudadas de Geissospermum selecionados para este estudo.

Table 1 - Data from the Geissospermum selected for that study.

\begin{tabular}{|c|c|c|}
\hline Espécie & Voucher & Local da coleta \\
\hline \multirow[t]{5}{*}{ Geissospermum argenteum } & INPA 15440 & Manaus - AM \\
\hline & INPA 174723 & Manaus - AM \\
\hline & INPA 19525 & Manaus - AM \\
\hline & INPA 195657 & Pres. Figueiredo - AM \\
\hline & INPA 257664 & Pres. Figueiredo - AM \\
\hline \multirow[t]{3}{*}{ Geissospermum laeve } & HAMAB 013926 & Tucumunaque - AP \\
\hline & INPA 17298 & Rio Preto da Eva - AM \\
\hline & INPA 85969 & Pando (Bolívia) \\
\hline \multirow[t]{2}{*}{ Geissospermum reticulatum } & HAMAB 06387 & Macapá - AP \\
\hline & INPA 180732 & Costa Marques - RO \\
\hline \multirow[t]{6}{*}{ Geissospermum sericeum } & HAMAB 03814 & Camaipi - AP \\
\hline & INPA 206633 & Itacoatiara - AM \\
\hline & MG 150198 & Almerim - PA \\
\hline & MG 209580 & Vitória do Xingu - PA \\
\hline & MG 59351 & Altamira - PA \\
\hline & MG 72224 & Almerim - PA \\
\hline \multirow[t]{5}{*}{ Geissospermum urceolatum } & INPA 17572 & Manaus - AM \\
\hline & INPA 181857 & Manaus - AM \\
\hline & INPA 232014 & Manaus - AM \\
\hline & INPA 95630 & Beni (Bolivia) \\
\hline & INPA 95683 & Beni (Bolivia) \\
\hline
\end{tabular}

foram analisados sob luz polarizada para evidenciar constituintes celulares de natureza birrefringente.

Os espécimes de Geissospermum foram comparados entre si, de acordo com as características estruturais dos órgãos vegetativos (68 caracteres) e mediante uma matriz binária (Tab. 2). A matriz foi construída no programa Microsoft Excel 2016 e posteriormente exportada para o programa PAST 2.17c (Hammer et al. 2001). Métodos estatísticos multivariados como análises de agrupamento (cluster análises) foram conduzidas para a série de dados. $\mathrm{O}$ fenograma foi construído através do algoritmo de agrupamento UPGMA utilizando o índice de Jaccard (Sneath \& Sokal 1973).

\section{Resultados}

Caule

Em todos os espécimes de Geissospermum analisados e em seção transversal, o caule é cilíndrico (Fig. 1a) A epiderme é unisseriada com células de aspecto papiloso (Fig. 1b). O córtex é predominantemente parenquimático, composto por quatro a seis camadas de células. Adjacente, nota-se um anel esclerenquimático que envolve totalmente o sistema vascular (Fig. 1a).

O sistema vascular encontra-se com o câmbio vascular instalado. Esta região é caracterizada pela presença do floema externo, onde apresenta inúmeras fibras de floema dispostas em faixa contínua e associados a cristais prismáticos (Fig. $1 \mathrm{c}, \mathrm{d})$, e o floema interno, sendo ambos limitando o xilema. Os elementos de vaso apresentam ou não apêndices apicais, com placas de perfuração simples (Fig. 1e) e pontoações (Fig. 1f).

A região medular é ampla e pode apresentar preenchimento uniforme de esclereídes, como em G. sericeum (Fig. 1g), ou preenchimento desuniforme nas demais espécies, através de esclereídes isolados (Fig. 1h) ou em calotas. 
Tabela 2 - Matriz binária dos caracteres anatômicos das espécies de Geissospermum. Valores: $0=$ ausência; $1=$ presença. Abreviações: $\arg =$ G. argenteum; lea $=$ G. laeve $;$ ret $=$ G. reticulatum; ser $=$ G. sericeum; urc $=$ G. urceolatum . Table 2 - Binary matrix of the anatomical characters of the Geissospermum species. Values: $0=$ absence; $1=$ presence. Abbreviations: $\arg =G$. argenteum $;$ lae $=G$. laeve; $\mathrm{ret}=$ G. reticulatum $; \mathrm{ser}=G$. sericeum $;$ urc $=G$. urceolatum.

\begin{tabular}{|c|c|c|c|c|c|}
\hline Características & arg & lae & ret & ser & urc \\
\hline Células epidérmicas com parede anticlinais da face adaxial retas & 1 & 0 & 1 & 1 & 1 \\
\hline Células epidérmicas com parede anticlinais da face adaxial sinuosas & 0 & 1 & 0 & 0 & 0 \\
\hline Células epidérmicas com parede anticlinais da face abaxial retas & 1 & 0 & 1 & 1 & 1 \\
\hline Células epidérmicas com parede anticlinais da face abaxial sinuosas & 0 & 1 & 0 & 0 & 0 \\
\hline Estômatos paracíticos & 1 & 1 & 1 & 1 & 1 \\
\hline Estômatos no mesmo nível epidérmico & 1 & 1 & 1 & 1 & 1 \\
\hline Tricomas tectores persistentes nas folhas adultas & 1 & 0 & 0 & 1 & 0 \\
\hline Tricomas tectores glabros nas folhas adultas & 0 & 1 & 1 & 0 & 1 \\
\hline Região mediana do limbo com cutícula delgada em ambas as faces & 1 & 1 & 1 & 1 & 1 \\
\hline Região mediana do limbo com células epidérmicas tabulares na face adaxial & 1 & 1 & 1 & 1 & 1 \\
\hline Região mediana do limbo com células epidérmicas de aspecto papiloso na face abaxial & 1 & 0 & 0 & 1 & 0 \\
\hline Região mediana do limbo com células epidérmicas tabulares na face abaxial & 0 & 1 & 1 & 1 & 1 \\
\hline Região mediana do limbo com células epidérmicas de aspecto arredondado na face abaxial & 0 & 1 & 0 & 0 & 0 \\
\hline Mesofilo dorsiventral & 1 & 1 & 1 & 1 & 1 \\
\hline Mesofilo com uma camada de parênquima paliçádico & 0 & 1 & 1 & 1 & 1 \\
\hline Mesofilo com duas camadas de parênquima paliçádico & 1 & 0 & 0 & 0 & 1 \\
\hline Mesofilo com parênquima lacunoso de arranjo compacto & 1 & 1 & 1 & 1 & 1 \\
\hline Mesofilo com parênquima lacunoso de arranjo frouxo & 0 & 1 & 0 & 0 & 0 \\
\hline Mesofilo com feixe vascular colateral & 1 & 1 & 1 & 1 & 1 \\
\hline Mesofilo com feixe vascular envolto totalmente por esclerênquima & 1 & 1 & 1 & 1 & 1 \\
\hline Margem foliar levemente revoluta & 1 & 1 & 1 & 1 & 1 \\
\hline Margem foliar com células epidérmicas de aspecto papiloso & 0 & 1 & 1 & 1 & 1 \\
\hline Margem foliar com células epidérmicas paliçada & 1 & 0 & 0 & 1 & 0 \\
\hline Margem foliar com parênquima contínuo & 1 & 0 & 0 & 0 & 0 \\
\hline Margem foliar com colênquima & 1 & 1 & 1 & 1 & 1 \\
\hline Margem foliar com esclereídes & 1 & 1 & 1 & 1 & 0 \\
\hline Nervura central biconvexa & 1 & 1 & 1 & 1 & 1 \\
\hline Nervura central com epiderme unisseriada em ambas as faces & 1 & 1 & 1 & 1 & 1 \\
\hline Nervura central com cutícula delgada em ambas as faces & 1 & 1 & 1 & 1 & 1 \\
\hline Nervura central com tricomas tectores na face abaxial & 1 & 0 & 0 & 1 & 0 \\
\hline Nervura central com células epidérmicas de aspecto papiloso na face adaxial & 0 & 1 & 1 & 0 & 1 \\
\hline Nervura central com células epidérmicas paliçada na face adaxial & 1 & 0 & 0 & 1 & 0 \\
\hline Nervura central com células epidérmicas de aspecto papiloso na face abaxial & 1 & 1 & 1 & 1 & 1 \\
\hline Nervura central com feixe vascular bicolateral & 1 & 1 & 1 & 1 & 1 \\
\hline Nervura central com colênquima em ambas as faces & 1 & 1 & 1 & 1 & 1 \\
\hline Nervura central com braquiesclereídes na face adaxial & 1 & 1 & 1 & 1 & 0 \\
\hline Nervura central com braquiesclereídes na face abaxial & 1 & 1 & 1 & 1 & 1 \\
\hline
\end{tabular}




\begin{tabular}{|c|c|c|c|c|c|}
\hline Características & $\arg$ & lae & ret & ser & ure \\
\hline Nervura central com esclerênquima envolvendo o feixe vascular & 1 & 1 & 1 & 1 & 1 \\
\hline Nervura central com feixe bicolateral & 1 & 1 & 1 & 1 & 1 \\
\hline Nervura central com feixe vascular em arco fechado & 1 & 1 & 1 & 0 & 0 \\
\hline Nervura central com feixe vascular circular & 0 & 0 & 0 & 1 & 0 \\
\hline Nervura central com feixe vascular em arco aberto e um feixe associado & 0 & 0 & 0 & 0 & 1 \\
\hline Pecíolo com tricomas tectores & 1 & 1 & 1 & 1 & 1 \\
\hline Pecíolo de formato cilíndrico & 0 & 0 & 0 & 1 & 0 \\
\hline Pecíolo de formato plano-convexo com duas expansões adaxiais & 1 & 0 & 0 & 0 & 0 \\
\hline Pecíolo de formato plano-convexo sem expansões adaxiais & 1 & 1 & 1 & 0 & 1 \\
\hline Pecíolo com epiderme de aspecto papiloso & 1 & 1 & 1 & 1 & 1 \\
\hline Pecíolo com braquiesclereídes apenas na face abaxial do córtex & 0 & 0 & 0 & 0 & 1 \\
\hline Pecíolo com braquiesclereídes predominante na face abaxial do córtex & 0 & 1 & 1 & 1 & 0 \\
\hline Pecíolo com braquiesclereídes uniforme no córtex & 1 & 0 & 0 & 1 & 0 \\
\hline Pecíolo com feixe vascular cilíndrico & 0 & 0 & 0 & 1 & 0 \\
\hline Pecíolo com feixe vascular em arco com extremidades convolutas & 0 & 0 & 0 & 0 & 1 \\
\hline Pecíolo com feixe vascular em arco conspícuo & 1 & 1 & 1 & 0 & 0 \\
\hline Caule com tricomas tectores & 1 & 1 & 1 & 1 & 1 \\
\hline Caule com epiderme de aspecto papiloso & 1 & 1 & 1 & 1 & 1 \\
\hline Caule com anel de esclerênquima circundando o sistema vascular & 1 & 1 & 1 & 1 & 1 \\
\hline Caule com preenchimento uniforme de esclereídes na região medular & 0 & 0 & 0 & 1 & 0 \\
\hline Caule com preenchimento desuniforme de esclereídes na região medular & 1 & 1 & 1 & 0 & 1 \\
\hline Nervuras primária pinada & 1 & 1 & 1 & 1 & 1 \\
\hline Nervuras secundárias de 10-14 pares & 1 & 1 & 1 & 1 & 1 \\
\hline Nervuras pseudo-secundárias & 1 & 1 & 1 & 1 & 1 \\
\hline Nervuras secundárias alternas & 1 & 1 & 1 & 1 & 1 \\
\hline Nervuras secundárias regulares & 1 & 1 & 1 & 1 & 1 \\
\hline Nervuras secundárias com espaçamento crescente & 1 & 0 & 0 & 1 & 0 \\
\hline Nervuras secundárias com espaçamento uniforme & 0 & 1 & 1 & 0 & 1 \\
\hline Nervuras terciárias reticuladas ao acaso & 1 & 1 & 1 & 1 & 1 \\
\hline Nervuras terciárias em ângulo agudo com a nervura primária & 1 & 1 & 1 & 1 & 1 \\
\hline Aréolas com braços dicotomizados & 1 & 1 & 1 & 1 & 1 \\
\hline
\end{tabular}

Inúmeros laticíferos estão aleatoriamente distribuídos na região cortical e medular (Fig. 1i).

\section{Pecíolo}

Em seção transversal, o pecíolo é cilíndrico em G. sericeum (Fig. 2a) e plano-convexo em $G$. argenteum, $G$. laeve, $G$. reticulatum e $G$. urceolatum (Fig. 2b). Contudo, em G. argenteum o pecíolo também pode variar a plano-convexo com duas expansões adaxiais conspícuas (Fig. 2c).
Em todas as espécies analisadas, o pecíolo é revestido por numerosos tricomas tectores filiformes (Fig. 2d), epiderme com aspecto papiloso e cutícula delgada. $\mathrm{O}$ córtex é predominantemente parenquimático, sendo constituído por 2-3 camadas de colênquima angular adjacente à epiderme, laticíferos (Fig. 2e), e numerosos braquiesclereídes associados com cristais prismáticos (Fig. 2f,g). Em G. argenteum e $G$. sericeum, os braquiesclereídes estão organizados aleatoriamente na região cortical, 

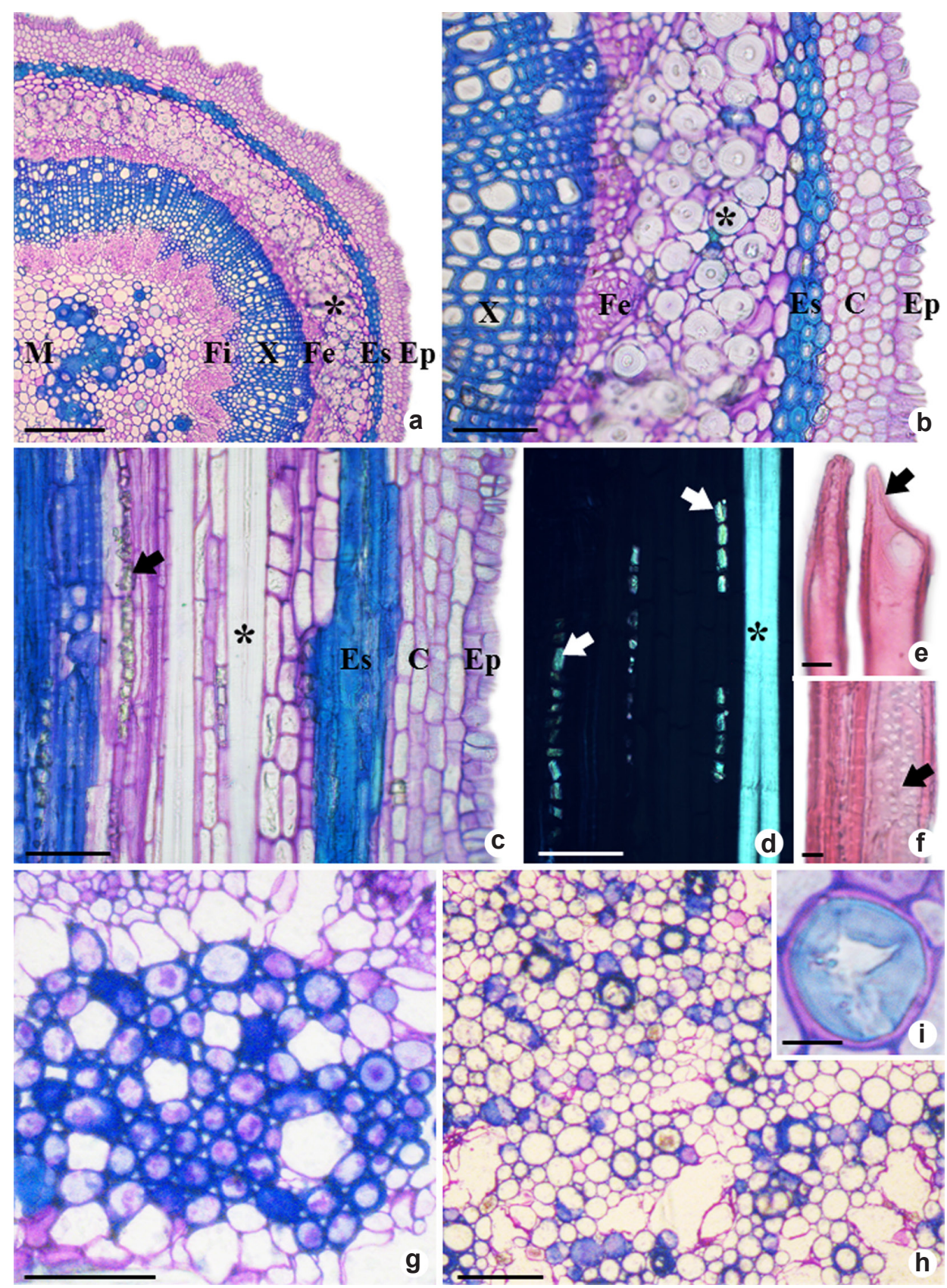

Figura 1 - a-i. Caule de Geissospermum spp. - a. vista geral de G. urceolatum; b. região do caule em G. urceolatum, notar fibras de floema (*); c. seção longitudinal do caule de G. argenteum evidenciando fileiras de cristais prismáticos (setas); d. fibras de floema e fileiras de cristais prismáticos em G. argenteum sob luz polarizada; e. elemento de vaso, notar placa de perfuração simples (seta) em G. laeve; f. elemento de vaso com pontoações (seta) em G. laeve; g. região medular com preenchimento uniforme de esclereídes em G. sericeum; h. região medular com preenchimento desuniforme de esclereídes em $G$. argenteum; i. laticífero em $G$. argenteum. $(\mathrm{C}=$ córtex; Ep = epiderme; Es = esclerênquima; Fe = floema externo; $\mathrm{Fi}=$ floema interno; $\mathrm{M}=$ medula; $\mathrm{X}=$ xilema). Barras: $\mathrm{a}=150 \mu \mathrm{m} ; \mathrm{b}-\mathrm{d}, \mathrm{g}, \mathrm{h}=50 \mu \mathrm{m} ; \mathrm{e}, \mathrm{f}, \mathrm{i}=25 \mu \mathrm{m}$.

Figure 1 - a-i. Stem of Geissospermum spp. - a. overview of G. urceolatum; b. regions of the stem in G. urceolatum, note phloem fiber (*); c. longitudinal section of the stem of $G$. argenteum evidencing rows of prismatic crystals (arrows); d. phloem fibers and rows of prismatic crystals in G. argenteum under polarized light; e. vessel element, note perforation plate (arrow) in G. laeve; f. vessel element with pitting (arrow) in G. laeve; g. medullary region with uniform sclereid filling in G. sericeum; h. medullary region with random sclereid filling in G. argenteum; i. laticifers $\left(^{*}\right)$ in $\mathrm{G}$. argenteum $(\mathrm{C}=$ cortex; $\mathrm{Ep}=$ epidermis; Es = esclerenchima; $\mathrm{Fe}=$ external phloem; $\mathrm{Fi}=$ internal phloem; $\mathrm{M}$ $=$ medulla; $\mathrm{X}=$ xylem). Bars: $\mathrm{a}=150 \mu \mathrm{m} ; \mathrm{b}-\mathrm{d}, \mathrm{g}, \mathrm{h}=50 \mu \mathrm{m} ; \mathrm{e}, \mathrm{f}, \mathrm{i}=25 \mu \mathrm{m}$. 

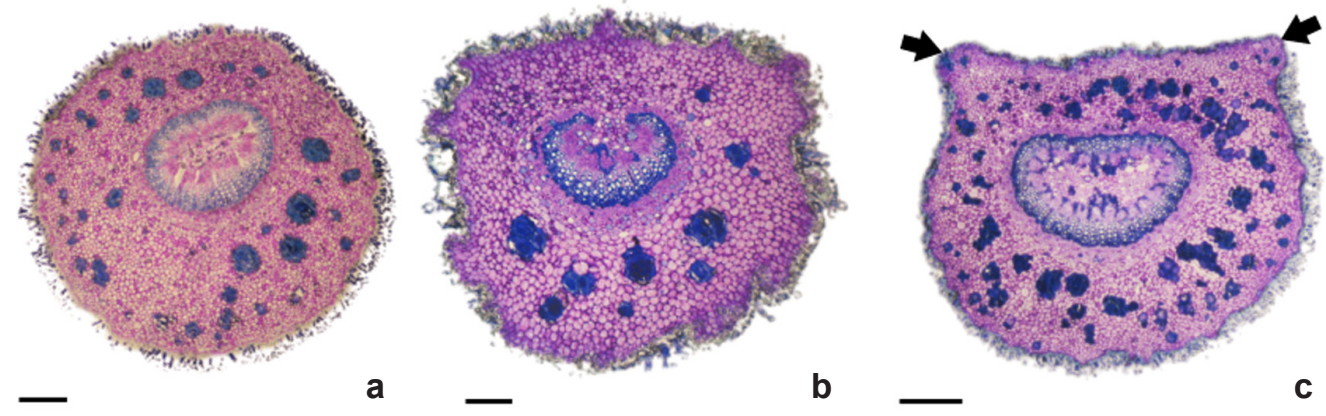

b

C
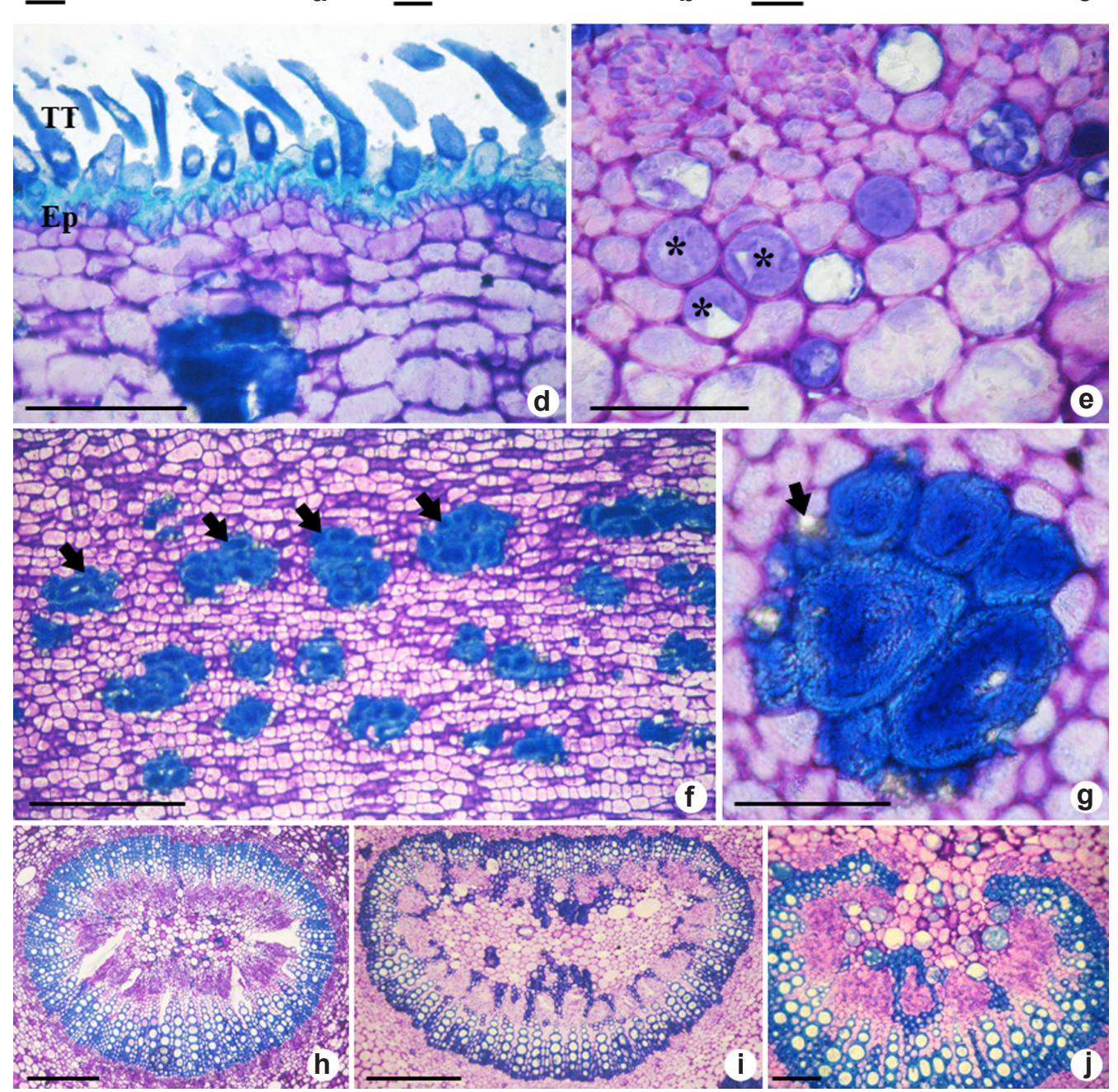

Figura 2 - a-j. Pecíolo de Geissospermum spp. - a-c. vista geral - a. contorno cilíndrico em G. sericeum; b. contorno planoconvexo em G. urceolatum; c. contorno plano convexo com duas expansões adaxiais (setas) em G. argenteum; d. epiderme papilosa com tricomas em G. argenteum; e-g. córtex-e. laticíferos (*) em G. urceolatum; f. corte longitudinal evidenciando braquiesclereídes (setas) em G. sericeum; g. braquiesclereídes associados com cristais prismáticos (seta) em G. urceolatum; $\mathrm{h}$-j. contorno do feixe vascular - h. cilíndrico em G. sericeum; i. arco conspícuo em G. argenteum; j. arco com as extremidades convolutas em G. urceolatum. (Ep = epiderme; TT $=$ tricomas tectores.) Barras: $\mathrm{a}-\mathrm{c}=300 \mu \mathrm{m} ; \mathrm{d}-\mathrm{f}=100 \mu \mathrm{m} ; \mathrm{h}-\mathrm{j}=200 \mu \mathrm{m}$. Figure 2 - a-j. Petiole of Geissospermum spp. - a-c. overview - a. cylindrical contour in G. sericeum; b. plane-convex contour in G. urceolatum; c. convex plane contour with two adaxial expansions in G. argenteum; d. papillose epidermis with trichomes in G. argenteum; e-g. cortex - e. laticifers (*) in G. urceolatum; f. longitudinal section showing brachyceclereides (arrows) in G. sericeum; g. brachysclereides associated with prismatic crystals (arrow) in G. urceolatum; h-j. contour of the vascular bundle - h. cylindrical in $G$. sericeum; i. conspicuous arch shape in $G$. argenteum; $\mathrm{j}$. arch shape with convoluted extremity in G. urceolatum. ( $\mathrm{Ep}=$ epidermis; $\mathrm{TT}=$ tectory trichomes.) Bars: $\mathrm{a}-\mathrm{c}=300 \mu \mathrm{m} ; \mathrm{d}-\mathrm{f}=100$ $\mu \mathrm{m} ; \mathrm{h}-\mathrm{j}=200 \mu \mathrm{m}$. 
enquanto que em G. laeve e G. reticulatum estão concentrados na face abaxial e em G. urceolatum apenas na face abaxial.

O sistema vascular das espécies estudadas é bicolateral (Fig. 2h-j). Sua organização varia entre as espécies, podendo ser cilíndrico a elíptico em G. sericeum (Fig. 2h), em arco conspícuo em G. argenteum (Fig. 2i), G. laeve e G. reticulatum ou em arco com as extremidades convolutas em G. urceolatum (Fig. 2j).

\section{Lâmina foliar}

Nas espécies estudadas, a lâmina foliar é hipoestomática com predominância de estômatos paracíticos (Fig. 3a). Em vista frontal, as células epidérmicas apresentam paredes anticlinais retas (Fig. 3b) ou sinuosas em G. laeve (Fig. 3c). Na face abaxial, é possível distinguir dois grupos na epiderme de Geissospermum: o primeiro é caracterizado por densos tricomas tectores e filiformes persistentes em G. argenteum (Fig. 3d,e) e G. sericeum, e o segundo pela glabrescência das folhas adultas de G. laeve (Fig. 3f,g), G. reticulatum (Fig. 3h,i) e G. urceolatum.

Em todas as espécies e em seção transversal, a região mediana foliar apresenta células epidérmicas da face adaxial tabulares e cutícula delgada (Fig. 3d-i). As células epidérmicas, na face abaxial, são tabulares em $G$. reticulatum (Fig. 3h), G. sericeum e G. urceolatum. Em G. laeve algumas células podem apresentar aspecto arredondado na face adaxial (Fig. 3f), enquanto em $G$. argenteum todas as células epidérmicas na face adaxial apresentam aspecto arredondado (Fig. 3d). Os estômatos estão situados no mesmo nível epidérmico em todas as espécies (Fig. 3f).

O mesofilo é dorsiventral com uma única camada de parênquima paliçádico em $G$. laeve (Fig. 3f) e G. reticulatum (Fig. 3h) ou até duas camadas nas demais espécies (Fig. 3d). Frequentemente observa-se a presença de idioblastos cristalíferos no parênquima paliçádico de todas as espécies (Fig. 3h). Os feixes vasculares de menor calibre são colaterais, envoltos por esclerênquima e cristais prismáticos (Fig. 3d,f,h).

A margem foliar é levemente revoluta, apresenta epiderme uniestratificada com flanges cuticulares em G. argenteum (Fig. 3e) e $G$. sericeum. O parênquima paliçádico é contínuo na margem em G. argenteum (Fig. $3 \mathrm{e}$ ) e interrompido nas demais espécies (Fig. 3g,i). A margem foliar de todas as espécies é sustentada por colênquima angular (Fig. 3e,g), às vezes, apresentando esclereídes (Fig. 3i).

Em seção transversal, as espécies de Geissospermum apresentam formato da nervura central biconvexo (Fig. 4a-c). A epiderme é unisseriada, com presença de cutícula delgada (Fig. 4d-f). Na face adaxial, as células epidérmicas são organizadas em paliçada em G. argenteum (Fig. 4d) e G. sericeum, e com células de aspecto papiloso em G. laeve (Fig. 4e), G. reticulatum e G. urceolatum. Na face abaxial, as células epidérmicas apresentam aspecto papiloso ou arredondado em todas as espécies estudadas (Fig. 4f).

O córtex da nervura central é formado por 2-3 camadas de colênquima angular adjacente à epiderme (Fig. 4d-f). Inúmeros braquiesclereídes associados a cristais prismáticos estão aleatoriamente distribuídos na região cortical (Fig. 4g,h), estando ausentes na face adaxial apenas em $G$. urceolatum.

O feixe vascular da nervura central é bicolateral (Fig. 4j,k), podendo apresentar três padrões de organização dos feixes: arco conspícuo em $G$. argenteum, $G$. laeve e $G$. reticulatum (Fig. 4a), cilíndrico em G. sericeum (Fig. 4b), e arco com a extremidade convoluta com um feixe dorsal em G. urceolatum (Fig. 4c). Numerosos laticíferos estão distribuídos no parênquima cortical e medular (Fig. 4i).

\section{Venação}

Em todos os indíviduos de Geissospermum analisados, as nervuras primárias são pinadas, retas e afinam conforme se aproximam do ápice (Fig. 5a,b). As nervuras secundárias apresentam padrão de venação eucamptódroma com 10-14 pares. Estas nervuras são alternas, regulares, com espaçamento aumentando da base para o ápice em G. argenteum e G. sericeum, e espaçamento uniforme nas demais espécies. Em todas as espécies foram observadas nervuras pseudosecundárias.

As nervuras terciárias apresentam um padrão aleatório de reticulação, formando ângulo agudo em relação as nervuras primárias. As aréolas apresentam braços dicotomizados (Fig. $5 c-e)$.

Análise fenética

A análise fenética resultou em um fenograma (Fig. 6), onde grupos e subgrupos podem ser definidos. O grupo A é formado por 

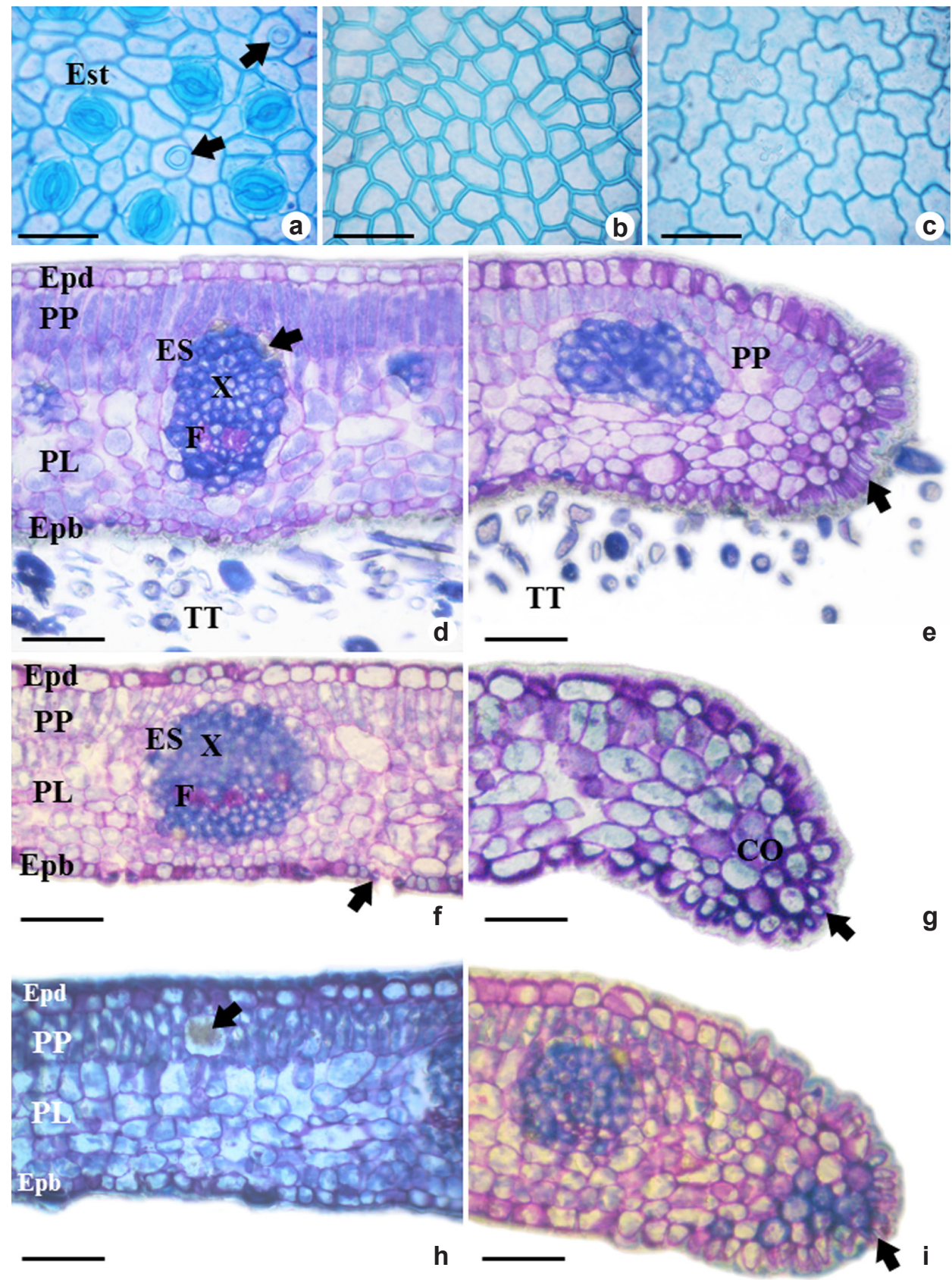

Figura 3 - a-i. Limbo foliar de Geissospermum spp. - a-c. superfície foliar - a. face abaxial de G. argenteum, evidenciando cicatriz de tricomas (setas); b. face adaxial de G. reticulatum; c. face adaxial de G. laeve; d,f,h. região mediana em corte transversal - d. feixe vascular rodeados por cristais prismáticos (seta) em G. argenteum; f. nível dos estômatos (seta) em G. laeve; h. idioblasto cristalífero (seta) em G. reticulatum; e,g,i. margem em seção transversal-e. epiderme com flanges cuticulares em G. argenteum; g. epiderme com aspecto papiloso em G. laeve; i. epiderme com aspecto papiloso em $G$. reticulatum. $(\mathrm{Epb}=$ epiderme abaxial; Epd = epiderme adaxial; $\mathrm{ES}=$ bainha esclerenquimática; $\mathrm{Est}=$ estômatos; $\mathrm{F}=$ floema; $\mathrm{PL}=$ parênquima lacunoso; $\mathrm{PP}=$ parênquima paliçádico; $\mathrm{TT}=$ Tricomas tectores; $\mathrm{X}=$ xilema). Barras: $50 \mu \mathrm{m}$. Figure 3 - a-i. Leaf blade of Geissospermum spp. - a-c. leaf surface - a. abaxial face of G. argenteum, showing cicatrice of trichomes (arrows); b. adaxial face of $G$. reticulatum; c. adaxial face of $G$. laeve; d,f,h. middle region in cross-section - d. vascular bundle surrounded by prismatic crystals (arrow) in G. argenteum; f. stomata level (arrow) in G. laeve; h. crystalline idioblast (arrow) in G. reticulatum; e,g,i. margin in transverse view - e. epidermis with cuticular flanges (arrow) in G. argenteum; g. papillose aspect epidermis in G. laeve; i. papillose aspect epidermis in G. reticulatum; $(\mathrm{Epb}=$ abaxial epidermis; $\mathrm{Epd}=$ adaxial epidermis; $\mathrm{ES}=$ sclerenchymatic sheath; Est $=$ stomata; $\mathrm{F}=$ phloem; $\mathrm{PL}=$ spongy parenchyma; $\mathrm{PP}=$ palisade parenchyma; $\mathrm{TT}=$ tectory trichomes; $\mathrm{X}=\mathrm{xylem})$. Bars: $50 \mu \mathrm{m}$. 

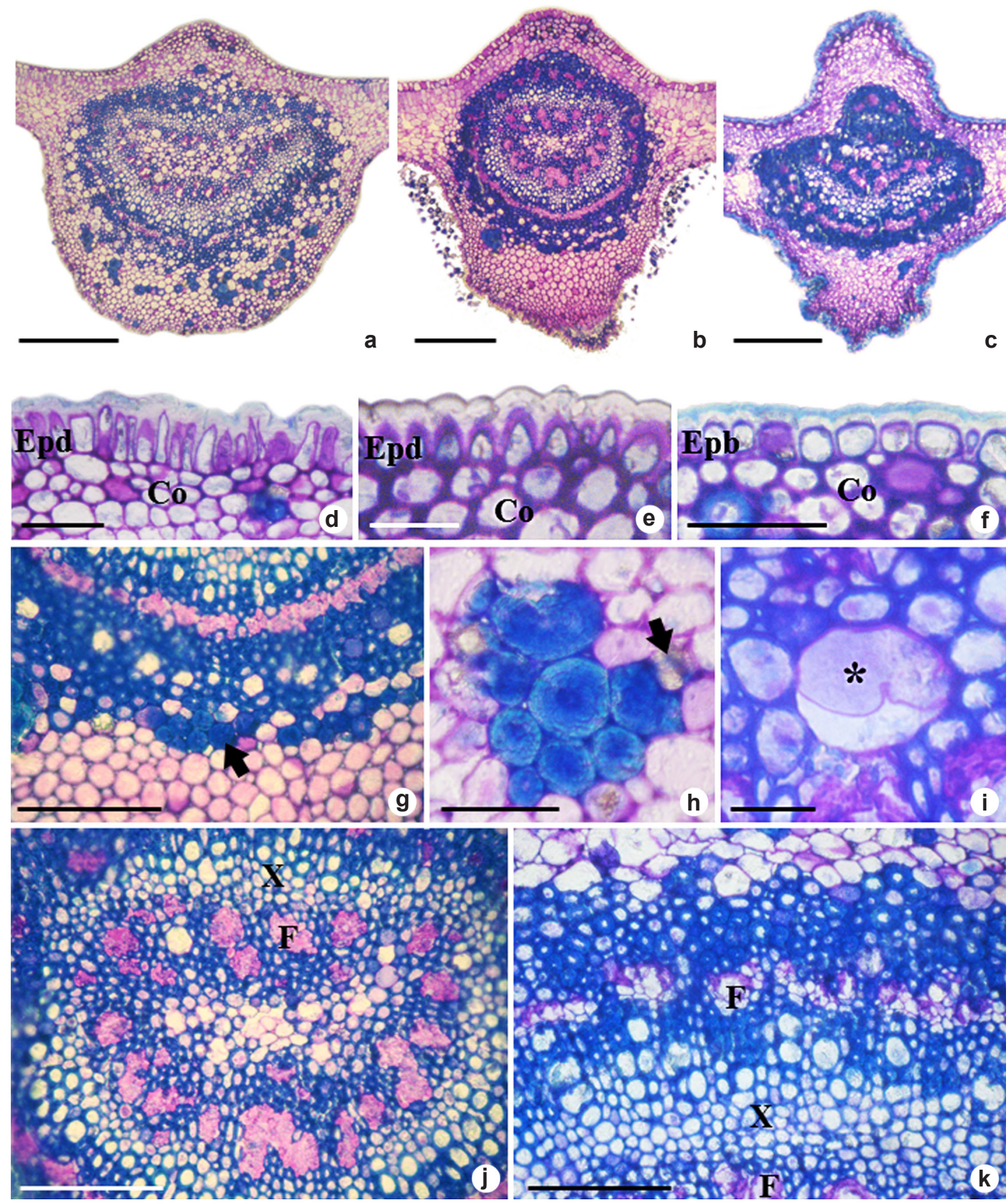

Figura 4 -a-k. Nervura central de Geissospermum spp. - a-c. vista geral - a. G. reticulatum; b. G. sericeum; c. G. urceolatum; d-f. epiderme - d. em paliçada na face adaxial de G. argenteum; e. com aspecto papiloso na face adaxial de G. laeve; f. com células de aspecto arredondado na face abaxial de G. reticulatum; g-i. córtex - g. braquiesclereídes (seta) em G. sericeum; h. notar braquiesclereídes associados com cristais prismáticos (seta) em G. argenteum; i. laticífero (*) em G. argenteum; j,k. feixe vascular -j. G. sericeum; k. G. argenteum. $(\mathrm{F}=$ Floema; $\mathrm{X}=$ xilema). Barras: a-c $=300 \mu \mathrm{m} ; \mathrm{d}, \mathrm{f}, \mathrm{i}=50 \mu \mathrm{m} ; \mathrm{g}, \mathrm{j}, \mathrm{k}=100 \mu \mathrm{m}$. Figure 4 -a-k. Central vein of Geissospermum spp. - a-c. overview - a. G. reticulatum; b. G. sericeum; c. G. urceolatum; d-f. epidermis - d. palisade on the adaxial face of G. argenteum; e. papillose on the adaxial face of G. laeve; f. with rounded aspect cells in the abaxial face of G. reticulatum; g-i. cortex - g. brachionsclereids (arrow) in G. sericeum; h. note brachysclereides associated with prismatic crystals (arrow) in G. argenteum; i. laticifers $(*)$ in G. argenteum; j,k. vascular bundle $-\mathrm{j}$. G. sericeum; k. G. argenteum. $(\mathrm{F}=$ phloem; $\mathrm{X}=$ xylem). Bars: a-c $=300 \mu \mathrm{m} ; \mathrm{d}, \mathrm{e}, \mathrm{f}, \mathrm{i}=50 \mu \mathrm{m} ; \mathrm{g}, \mathrm{j}, \mathrm{k}=100 \mu \mathrm{m}$. 

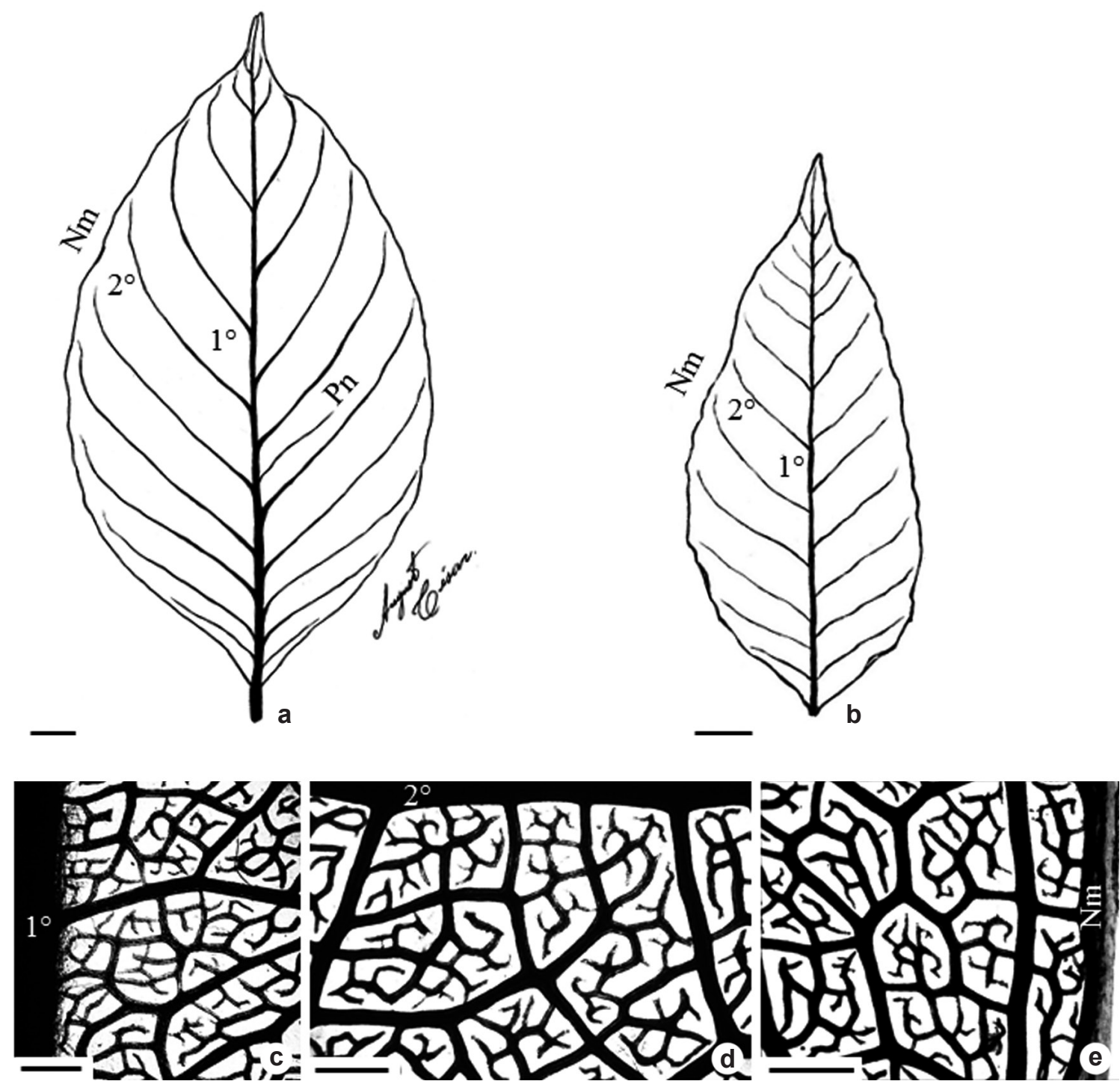

Figura 5 - a-e. Venação de Geissospermum spp. - a. G. argenteum; b. G. urceolatum; c-e. G. reticulatum. $(\mathrm{Nm}=\mathrm{Nervura}$ marginal; $\mathrm{Pn}=$ Pseudo-nervura secundária). Barras: $\mathrm{a}, \mathrm{b}=1 \mathrm{~cm} ; \mathrm{c}-\mathrm{e}=200 \mu \mathrm{m}$.

Figure 5 - a-e. Venation of Geissospermum spp. - a. G. argenteum; b. G. urceolatum; c-e. G. reticulatum. (Nm = marginal rib; $\mathrm{Pn}=$ secondary pseudo-rib). Bars: $\mathrm{a}, \mathrm{b}=1 \mathrm{~cm} ; \mathrm{c}-\mathrm{e}=200 \mu \mathrm{m}$.

G. argenteum e G. sericeum no qual as principais características compartilhadas são pecíolo com braquiesclereídes uniformes no córtex, células epidérmicas com cristas cuticulares na margem foliar e na face adaxial, células em paliçada na nervura central, e tricomas tectores persistentes na face abaxial da lâmina foliar adulta. $\mathrm{O}$ grupo B é composto por $G$. urceolatum e pelo subgrupo $\mathrm{C}$, que juntos apresentam tricomas tectores glabros na lâmina foliar adulta, nervura central com células epidérmicas com aspecto papilosos na margem foliar e na face adaxial da nervura central. O subgrupo C é formado por $G$. laeve e $G$. reticulatum e que tem como característica exclusiva a presença de braquiesclereídes concentrados principalmente na face adaxial do pecíolo.

Com base nos principais caracteres anatômicos, foi elaborada uma chave dicotômica de identificação para Geissospermum. 


\begin{tabular}{ccccccccc}
\multicolumn{1}{c}{ Similaridade } \\
0,55 & 0,60 & 0,65 & 0,70 & 0,75 & 0,80 & 0,85 & 0,90 & 0,95 \\
\hline
\end{tabular}

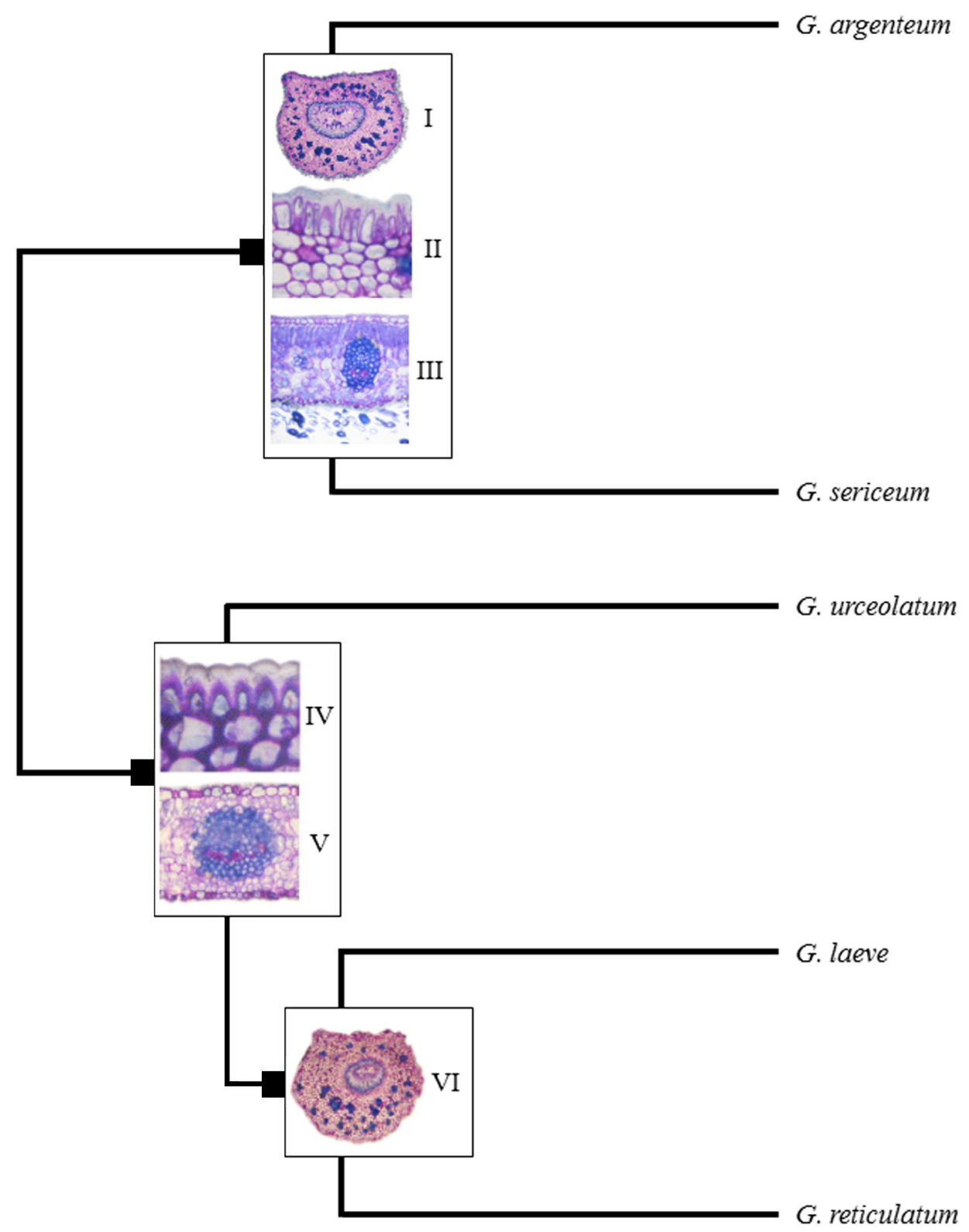

Figura 6 - Fenograma gerado a partir da similaridade das estruturais do caule, pecíolo e limbo foliar das espécies estudadas de Geissospermum - I. braquiesclereídes uniforme no pecíolo; II. células epidérmicas em paliçada na face adaxial da nervura central; III. tricomas tectores persistentes na lamina foliar adulta; IV. células epidérmicas de aspecto papiloso na face adaxial da nervura central; V. lâmina foliar glabra; VI. braquiesclereídes concentrados na face abaxial do pecíolo. (A,B = grupos; $\mathrm{C}=$ subgrupo).

Figure 6 -Phenogram generated from the similarity of the stem, petiole and leaf blade characters of the studied species of Geissospermum - I. brachysclereids uniform on petiole; II. epidermal cells in palisade on the adaxial face of the central vein and leaf margin; III. persistent tectory trichomes in adult leaf blade; IV. papillary epidermal cells on the adaxial face of the central vein and leaf margin; V. glabrous leaf blade; VI. brachysclereids concentrated on the abaxial face of petiole. (A,B = groups; $\mathrm{C}=$ subgroup). 


\section{Chave de identificação das espécies de Geissospermum}

1. Face abaxial do limbo foliar adulto com tricomas tectores persistentes.

2. Pecíolo de contorno plano-convexo, às vezes com duas expansões adaxiais; sistema vascular do pecíolo em arco compícuo; caule com preenchimento desuniforme de esclereídes na região medular; margem foliar com parênquima contínuo Geissospermum argenteum

2'. Pecíolo de contorno cilíndrico, sem expansões adaxiais; sistema vascular do pecíolo cilíndrico; caule com preenchimento uniforme de esclereídes na região medular; margem foliar com parênquima interrompido.

Geissospermum sericeum

1'. Face abaxial do limbo foliar adulto com tricomas tectores ausentes

3. Pecíolo com sistema vascular em arco com as extremidades convolutas; braquiesclereídes apenas na face abaxial do pecíolo Geissospermum urceolatum

3'. Pecíolo com sistema vascular em arco compícuo; braquiesclereídes em ambas as faces concentrados principalmente na face abaxial do pecíolo.

4. Células epidérmicas da lâmina foliar com paredes anticlinais sinuosas

Geissospermum laeve

4'. Células epidérmicas da lâmina foliar com paredes anticlinais retas

Geissospermum reticulatum

\section{Discussão}

De modo geral, Geissospermum apresenta características anatômicas conservativas e já relatadas em outros representantes de Apocynaceae e também de Aspidospermeae, como epiderme uniestratificada, presença de tricomas tectores, estômatos paracíticos, mesofilo dorsiventral, sistema vascular do pecíolo em arco e cilíndrico, além da presença de idioblastos e laticíferos (Solereder 1908; Metcalfe \& Chalk 1979; Reis et al. 2013).

A presença dos tricomas tectores já foi relatada como uma importante ferramenta taxonômica para outras espécies de Aspidospermeae. Em revisão taxonômica de Geissospermum (Barbosa 2016), a persistência ou a glabrescência dos tricomas tectores para as diferentes espécies dos gêneros apresentou um padrão similar ao relatado em nosso estudo. Barbosa (2016) cita que, quando jovens, as lâminas foliares de todas as espécies de Geissospermum apresentam tricomas em ambas as faces. Todavia, ao chegar à fase adulta, somente em $G$. argenteum e G. sericeum as folhas apresentam indumento homogêneo e conspícuo. A primeira espécie apresenta indumento do tipo seríceo de aparência prateada na face abaxial e a segunda apresenta tricomas de cor acastanhada em ambas as faces.

Além das características anatômicas encontradas em G. argenteum e G. sericeum, Barbosa (2016), através da morfologia foliar, conseguiu diferenciá-las pelo pecíolo escabro e lâmina foliar discolor em G. argenteum, contrapondo com o pecíolo estrigoso e lâmina foliar concolor em G. sericeum.

Apesar da epiderme sofrer constantes alterações devido ao ambiente onde encontra-se exposta (Taiz \& Zeiger 2013), os diferentes tipos de células epidérmicas observadas nas folhas de Geissospermum podem ser empregados na taxonomia do grupo, devido ao tipo celular manterse constante em todos os exemplares das espécies analisadas.

Nos resultados apresentados, Geissospermum exibiu três padrões de contorno no pecíolo que se mostraram úteis na distinção entre espécies. O contorno do pecíolo é considerado um caráter estável, pois não sofre variação ambiental (Metcalfe \& Chalk 1979) e vem sendo empregado com êxito para auxiliar a identificação de espécies de várias famílias de angiospermas (eg., Rio et al. 2005, para Apocynaceae; Costa et al. 2010, para Monimiaceae; Moraes et al. 2011, para Rubiaceae; Ogundare \& Saheed 2012, para Rutaceae; Almeida Jr. et al. 2013, para Sapotaceae; Coutinho et al. 2012, para Fabaceae). Em Forsteronia foram relatados dois padrões de pecíolo (achatado dorsiventralmente e cilíndricos) (Rio et al. 2005), enquanto que em Aspidosperma, o mesmo estado de caráter auxiliou na identificação entre espécies (Reis et al. 2013)

Além do contorno do pecíolo, a disposição do sistema vascular e a presença de braquiesclereídes associados com cristais prismáticos já foram descritas em outras espécies da tribo e utilizados como caráter taxonômico (Reis et al. 2013). Em Geissospermum, a disposição destas estruturas 
apresentou um padrão entre as espécies, exibindo assim relevância taxonômica para o grupo.

O padrão das nervuras secundárias foi semelhante ao observado por Barbosa (2016) ao estudar Geissospermum. Em Aspidosperma, o padrão de venação variou de broquidródoma em A. carapanauba Pichon, A. excelsum Benth. e A. pyricollum Müll.Arg. a craspedódroma em $A$. album (Vahl) Benoist ex Pichon, A. desmanthum Benth. ex Müll.Arg. e A. spruceanum Benth. ex Müll.Arg. (Reis et al. 2013).

A placa de perfuração dos elementos vasculares encontradas no caule é considerada por Lisboa (1989) como um caráter importante na distinção entre espécies. No entanto, esta se apresentou comum a todas as espécies aqui estudadas e sem aplicação taxonômica interespecífica. Lens et al. (2009) reporta a presença de placa de perfuração do tipo simples em espécies das subfamílias Apocynoideae e Periplocoideae por eles estudadas, sugerindo ser esta uma característica comum a estes taxa.

Todas as espécies estudadas apresentaram mesofilo dorsiventral, sugerindo que esta seja uma característica conservativa para o gênero. Segundo Metcalfe \& Chalk (1979), este é o tipo de organização do mesofilo mais comumente encontrado em Apocynaceae, sendo que este padrão já foi relatado como tendo valor taxonômico para outras espécies da família (Rios et al. 2005). Nossos resultados também demonstram que a quantidade de camadas do parênquima paliçádico é variável entre indivíduos da mesma espécie de Geissospermum. Entretanto, tal característica aparenta ser uma mera resposta ambiental (Taiz \& Zeiger 2013) e, por este motivo, consideramos que não é um bom caráter para ser utilizado na taxonomia do gênero.

Os idioblastos cristalíferos encontrados no parênquima lacunoso de Geissospermum podem fornecer informações taxonômicas para o gênero, como já relatado em outros representantes da família (Metcalfe \& Chalk 1979), sendo as drusas o tipo de idioblasto mais comum. Todavia, consideramos que os idioblastos cristalíferos não devem ser considerados um caráter diagnóstico interespecífico em Geissospermum, pois são raros e sem um padrão aparente entre as espécies analisadas. Ademais, é relatado na literatura que essas estruturas tendem a variar em presença e número de acordo com variáveis ambientais (Metcalfe \& Chalk 1979), sendo que os cristais podem estar presentes em maior ou menor quantidade de acordo com a composição do solo onde a planta se encontra (Taiz \& Zeiger 2013).

$\mathrm{Na}$ análise fenética, foi possível observar que os grupos de espécies de Geissospermum que compartilham semelhanças anatômicas correspondem a pares de espécies já reconhecidas em estudos taxonômicos prévios. A semelhança morfológica entre $G$. argenteum e $G$. sericeum já havia sido apontada por Woodson (1939) e posteriormente por Barbosa (2016), por serem as únicas espécies do gênero a apresentarem indumento denso e conspícuo em folhas adultas, além de lâmina foliar e tubo da corola com formato e dimensões similares. O mesmo pode-se dizer de $G$. laeve e G. reticulatum. As similaridades entre estes dois taxa, especialmente quanto ao indumento dos ramos, formato do tubo da corola e da lâmina foliar já haviam sido apontados por Gentry (1984) na descrição original de G. reticulatum, e também relatado por Barbosa (2016). Por fim, o não agrupamento de G. urceolatum na análise fenética também está de acordo com trabalhos anteriores, que apontam o fácil reconhecimento da espécie pelas folhas com margem sinuosa e tubo da corola urceolada, características únicas deste táxon dentro do gênero.

Em resumo, nosso trabalho demonstra que a anatomia dos órgãos vegetativos provê importantes caracteres para a identificação de espécies de Geissospermum, permitindo sua distinção mesmo em materiais estéreis. As características como formato das células epidérmicas, persistência ou caducidade dos tricomas tectores na lâmina foliar adulta, disposição dos braquiesclereídeos, contorno e vascularização do pecíolo foram as mais importantes na aplicação taxonômica.

\section{Agradecimentos}

Aos curadores dos herbários Dr. Patrick Cantuária (HAMAB), Dr. Michael J.G. Hopkins (INPA) e Dr. Pedro L. Viana (MG), o apoio na obtenção das amostras; ao Msc. Camilo Veríssimo Barbosa, a identificação do material; e à CAPES, a concessão de bolsa de Mestrado ao primeiro autor.

\section{Referências}

Almeida-Jr. EB, Araújo JS, Santos-Filho FS \& Zickel CS (2013) Leaf morphology and anatomy of Manilkara Adans. (Sapotaceae) from northeastern Brazil. Plant Systematic and Evolution 299: 1-9.

Barbosa CVO (2016) Revisão taxonômica de Geissospermum Allemão (Apocynaceae). 
Dissertação de Mestrado. Universidade Federal Rural da Amazônica, Belém. 58p.

BFG - The Brazil Flora Group (2015) Growing knowledge: an overview of seed plant diversity in Brazil. Rodriguésia 66: 1085-1113.

Costa FF, Lima HRP, Cunha M \& Santos IS (2010) Leaf anatomy and histochemistry of Macropeplus dentatus (Perkins) I. Santos \& Peixoto and Macropeplus ligustrinus (Tul.) Perkins (Monimiaceae). Acta Botanica Brasilica 24: 852-861.

Coutinho IAC, Francino DMT, Azevedo AA \& Meira RMSA (2012) Anatomy of the extrafloral nectaries in species of Chamaecrista section Absus subsection Baseophyllum (LeguminosaeCaesalpinioideae). Flora 207: 427-435.

Endress ME, Schumann SL \& Meve U (2014) An updated classification for Apocynaceae. Phytotaxa 159: $175-194$.

Franklin GL (1945) Preparation of thin sections of synthetic resins and wood-resin composites, and a new macerating method for wood. Nature 155: 51.

Fuchs CH (1963) Fuchsin staining with $\mathrm{NaOH}$ clearing for lignified elements of whole plants or plant organs. Stain Technology 38: 141-144

Gentry AH (1984) New species and combination in Apocynaceae from Peru and adjacent Amazonia. Annals of the Missouri Botanical Garden 71: 1075-1081.

Hammer O, Harper DAT \& Rian PD (2001) Past: Palaeonthological statistics software package for education and data analysis. Version 1.37. Disponível em <http://palaeo-electronica. org/2001_1/past/issue1_01.htm>. Acesso em 23 outubro 2016.

Hickey LJ (1973) Classification of the architeture of dicotyledonous leaves. Division of paleobotany. American Journal of Botany 60: 17-33.

Johansen DA (1940) Plant microtechnique. McGrawHill, New York. 523p.

Lens F, Endress ME, Baas P, Jansen S \& Smets E (2009) Vessel grouping patterns in subfamilies apocynoideae and periplocoideae confirm phylogenetic value of wood structure within Apocynaceae. American Journal of Botany 96: 2168-2183.

Lisboa PLB (1989) Aspectos da anatomia sistemática do lenho de Iryanthera Warb. (Myristicaceae).
Boletim do Museu Paraense Emílio Goeldi. Série Botânica 5: 83-134.

Metcalfe CR \& Chalk L (1979) Anatomy of the dicotyledons. Systematic anatomy of leaf and stem, with a brief history of the subject. Clarendon Press, Oxford. 276p.

Mohan JSS \& Inamdar JA (1982) Leaf architecture of Apocynaceae. Proceedings of Indian Academy of Science (Plant Science) 91: 189-200.

Moraes TMDAS, Rabelo GR, Alexandrino CR, Silva Neto SJ \& Cunha M (2011) Comparative leaf anatomy and micromorphology of Psychotria species (Rubiaceae) from the Atlantic Rainforest. Acta Botanica Brasilica 25: 178-190.

O’Brien TP, Feder N \& McCully ME (1964) Polychromatic staining of plant cell walls by toluidine blue O. Protoplasma 59: 368-373.

Ogundare CS \& Saheed SA (2012) Foliar epidermal chacaracteres and petiole anatomy of four species of Citrus L. (Rutaceae) from south-western Nigeria. Blangladesh Journal Plant Taxon 19: 25-31.

Reis ARS, Potiguara RCV, Reis LP (2013) Anatomia foliar de Aspidosperma Mart. \& Zucc. (Apocynaceae). Enciclopedia Biosfera 9: 32063227.

Rio MCS, Kinoshita LS \& Castro MM (2005) Anatomia foliar como subsídio para a taxonomia de espécies de Forsteronia G.Mey. (Apocynaceae) dos cerrados paulistas. Revista Brasileira de Botânica 28: 713726.

Smith FH \& Smith EC (1942) Anatomy of the inferior ovary of Darbya. American Journal of Botany 29: 464-471.

Sneath PH \& Sokal RR (1973) Numerical taxonomy: the principles and practice of numerical classification. W.H. Freeman, San Francisco. 573p.

Solereder H (1908) Systematic anatomy of the dicotyledons. $2^{\text {a }}$ ed. Clarendon Press, Oxford. 1182 p.

Taiz L \& Zeiger E (2013) Fisiologia vegetal. 5 ed. Artmed, Porto Alegre. 954p.

Thiers B [continuamente atualizado] Index Herbariorum: a global directory of public herbaria and associated staff. New York Botanical Garden's Virtual Herbarium. Disponível em $<$ http://sweetgum.nybg. org/science/ih/>. Acesso em 2 dezembro 2016.

Woodson Jr. RE (1939) Apocynaceae. In: Smith AC (ed.). Lloydia 2: 207-209. 